\title{
Effects of exemplar scenarios on public preferences for energy futures using the my2050 scenario-building tool
}

Christina Demski ${ }^{1 *}$, Alexa Spence ${ }^{2}$, Nick Pidgeon ${ }^{1}$

${ }^{1}$ Understanding Risk Research Group, School of Psychology, Cardiff University, Cardiff CF10 3AT, UK

${ }^{2}$ Horizon Digital Economy Research/School of Psychology, University of Nottingham, Nottingham NG7 2TU, UK,

*Corresponding author: DemskiCC@ @ardiff.ac.uk 


\begin{abstract}
Understanding which energy future configurations provide publically acceptable levels of energy security, affordability, and environmental protection is critical for institutional decision-making. However, little is known about how scenarios influence energy preferences. Here we present nationally representative UK data on public preferences for energy futures using the my2050 scenario-building tool that engages people to consider the holistic complexities of system change. Engagement with the tool strengthened existing preferences for renewable energy and intentions to take personal action. Importantly, patterns of energy preferences were influenced by exemplar scenarios, which served as reference points that anchored choices. Carbon capture and storage, nuclear power, biofuels, and changes to heating and travel were particularly impacted by scenarios indicating uncertainty and ambivalence regarding these options. Scenarios (and scenario-building tools) are valuable for engaging citizens about future energy systems. However, care is required in their design and interpretation to reach robust conclusions about underlying preferences and acceptance.
\end{abstract}


Numerous countries across the world are currently planning system-wide energy transitions in order to address climate change while also maintaining reliable energy supplies (e.g. 1). In the UK the 2008 Climate Change Act commits the country to an $80 \%$ cut in its territorial emissions by the year 2050 as compared to 1990 levels (2). Developing a national pathway to achieve such system change, by exploring different potential future energy scenarios, is therefore important in determining energy policy. This is an inherently complex task and the focus of much academic and political scrutiny (e.g. 3-8). Most such national energy scenarios and policies derive from technical and economic assessments and evaluations, but struggle to consider other types of relevant societal values and interests (9-13). In this regard, public perspectives can provide insights into potential social opportunities and constraints of energy pathways, and in particular which aspects and configurations of system change will provide socially acceptable levels of energy security, affordability, and environmental protection. Considering public views in this way is also important because energy transitions as a whole will involve people and communities in multiple ways - from consumers deciding how they should use the services that energy provides, to the ways in which society as a whole grants energy system providers a social license to operate (14-15). While there exists a wealth of evidence reporting public views of individual supply-side technologies and infrastructure, or on particular aspects of energy demand-side change (e.g. 16-19), there is little research that meaningfully engages people with the complexities of system change as a whole (although see 20-26).

Many organisations across diverse sectors invest resources in developing and publishing their own scenarios to guide debates and decision-making about energy futures (e.g. 4, 8, 27-28). However, tools for engaging members of the public to develop their own scenarios for system change are only just emerging. Here we demonstrate how a scenario-building tool can be used to give insights into public views. We report a study eliciting nationally representative data using the 'my2050' energy futures tool first developed by the UK Department of Energy and Climate Change (DECC) and the Sciencewise-Expert Centre for Public Dialogue in Science and Innovation (see Figure 1). The my2050 tool represents a simplified version of the UK energy system (4, 29-30). It enables respondents to explore different energy futures to meet the UK's 2050 carbon target of an $80 \%$ cut in 
emissions by adjusting seven supply-side and seven demand-side levers each with four 'effort' levels (see Methods, Figure 1 and Supplementary Table 1 for details about the levers).

A particular strength of my2050 is its system-wide approach, whereby users are encouraged to explore their preferences about different supply and demand sectors in combination rather than in isolation from one another; as well as in the context of carbon targets and technical feasibility. This is significant because previous research has repeatedly observed the importance of context in influencing public support for, and opposition to, energy technologies and options $(6,24,31)$. As such, this approach focuses directly on the compromises and value trade-offs often implicit within the complex set of issues related to energy futures. This should elicit public preferences which are more robust, stable and realistic when compared to those elicited in isolation of wider system contexts and information (e.g. most attitude surveys).

While interactive scenario tools and my2050 in particular have important advantages, the assumptions that they make should not be viewed uncritically $(29,32)$. These tools also have the potential to restrict a participant's exploration and choices because they simplify what are in reality a set of highly complex technical, economic and social policy issues (additional commentary on the use of my2050 to engage members of the public are articulated in ref 14 and Supplementary Note 1). Furthermore, framing theory and research has long pointed to the ways in which the context and presentation of information will influence how concepts and ideas are perceived and evaluated (33). Within this wider literature, the influence of provided information as reference points (ideas or information that is used to compare or understand subsequent information) is of particular interest to the current study. We explore the effect of presenting exemplar starting scenarios within my2050, examining if people's final preferences as a result of using the tool differ when presented with example energy futures as compared to creating their own future without such examples. This is a form of framing relevant beyond the my 2050 tool because exemplar scenarios are used routinely in decision-making around energy futures (e.g. 4, 7) 
Specifically, we hypothesised that people might use the presented exemplar scenarios as reference points from which to explore their own preferences and values, and that the depiction of possible energy futures anchor people's subsequent evaluations. As such, we predicted that exemplar scenarios would significantly influence the energy futures people create using the my 2050 tool. Here we are drawing on theory on the anchoring and adjustment heuristic, which describes how people use information that has been provided as a starting (or reference) point and often do not adjust their judgements significantly away from this initial frame (34-35). The effect of such reference points has been found to be particularly pronounced when people make choices that are complex, unfamiliar or uncertain (36-38).

In the following, we therefore present energy future preferences elicited using the my 2050 tool and go on to explore the effects of using the tool. Our results demonstrate how exemplar scenarios can significantly influence people's choices and how the process of engagement overall can strengthen existing preferences.

\section{Public preferences for energy futures using my2050}

We utilised the my2050 tool alongside a survey of public perceptions of energy futures using a quota sample $(\mathrm{n}=1,800)$ drawn from Great Britain (England, Scotland and Wales) and collected online in August 2012. The sample is broadly nationally representative with regards to age, gender, employment status and geographic region. Figure 2 displays means and standard deviations of lever choices in the basic my2050 tool (referred to as 'no exemplar' condition). Figure 3a presents the percentage of our sample selecting each lever position in order to achieve the carbon reduction target. Aspects of carbon reduction that were particularly important to our sample appear to be demand-side efficiency measures within the home and the business sector, both of which received the highest effort, followed by renewable energy (solar, marine, hydro) and offshore wind options on the supplyside. Biofuels also played a significant part in these public pathways, although this finding needs to be interpreted with caution because it is difficult to reach the carbon target using my 2050 without 
including at least some biofuels. The options that received the least effort on average included reductions in manufacturing growth and home temperature, alongside nuclear power, and carbon capture and storage (CCS; described in the tool as 'clean coal and gas').

Figure 1 depicts the energy future based on modal responses for illustrative purposes. However, note that the interpretation of this modal 'public pathway' is based on the most frequently chosen lever positions, resulting in quite a balanced pathway for meeting the carbon target. This pathway includes high levels of renewable energy on the supply side and high levels of energy efficiency on the demand side (although in this future supply significantly exceeds demand). This however hides several key aspects of the data, and most importantly its variability. For example, several levers were associated with a spread in responses illustrated by the high standard deviations shown in Figure 2: specifically nuclear power, CCS, onshore wind, biofuels, and reducing home temperatures. At the other extreme little variability is evident for fossil fuels, with most participants including substantial reductions in fossil fuel use in their my2050 futures (note it is possible to meet the carbon target without making any effort on fossil fuels, but only about $1 \%$ of respondents did so).

\section{Framing preferences using exemplar scenarios}

Much information in the public domain on potential future energy pathways comes in the form of pre-defined scenarios (e.g. 4, 27-28). We therefore examined the effects of providing exemplar scenarios to people and whether they might act as reference points anchoring the final futures that people arrived at. Within the study we presented two commonly discussed future energy scenarios to additional sub-samples of our respondents. These sub-samples were also broadly nationally representative (see Methods).

The first exemplar was constructed to represent a 'high-technology future' and relied heavily on non-renewable low-carbon supply technologies to meet the carbon reduction target, particularly high levels of CCS and nuclear power $(\mathrm{n}=204)$. The second represented a 'low-carbon living future' 
and depicted a pathway where much of the effort relied on demand-side change, alongside high use of wind and other renewable energy sources $(n=210)$. For each sub-sample of respondents the supply and demand levers in the tool were first set to represent one of these futures (see Methods for exact starting positions of each lever) and they then had to adjust these lever positions according to their own preferences. This is in contrast to the original 'no exemplar' version of the tool where all levers were initially set to zero (defined as minimal effort/ no change from current trajectory).

We compared the lever choices of the two exemplar scenario conditions with the no exemplar condition using a series of parametric and non-parametric tests (see Method). The average lever choices for each condition are displayed alongside each other in Figure 2 (also see Supplementary Table 2 for full descriptive statistics). Figure $3 b$ and $c$ display the percentage of respondents selecting each lever position for the two exemplar scenario conditions.

Examining the average pathways across the three scenario conditions, two aspects are of note. First, differences between the average choices are clearly evident, with most levers showing differences across the three versions of the tool. Indeed, a multivariate analysis of variance test was found to be significant $(\mathrm{F}(28,4398)=4396, \mathrm{p}<0.05)$ indicating that the scenarios we presented to affected participants' choices. Furthermore, follow-up tests (analysis of variance and post-hoc t-tests with Bonferroni corrections; Supplementary Table 3) revealed significant differences across all three versions of the tool for almost all levers (see Figure 2). There was one clear exception: the reductions in manufacturing growth option was not found to be different across the three versions of the tool. The most common response was a low 'effort' level of 1 , corresponding to no change in manufacturing output (as opposed to an increase at level 0 and a decrease at levels 2 and 3; also see Supplementary Note 1). To confirm the findings from the parametric analysis, a series of nonparametric tests were also conducted in the form of Mann-Whitney $U$ tests (full results displayed in Supplementary Table 4). Here we find that onshore wind also showed no significant difference between the no exemplar and exemplar conditions. Levels included tended to indicate some support for onshore wind turbines, but less than for other renewable technologies. 
Second, and perhaps most critically, those differences evident between the no exemplar and exemplar versions of the tool were in the direction of the original starting points that respondents were presented with, clearly illustrating the effect of anchoring. For the 'high-technology future' we observed significantly higher levels of biofuels, nuclear power and CCS, coupled with lower effort for renewables and most demand-side choices. For the 'low-carbon living' scenario, we found significantly lower effort for non-renewable forms of supply and significantly higher effort on all renewable forms apart from onshore wind when compared to the other two conditions. Similarly, we found significantly higher inclusion of all demand-side options in the 'low-carbon living' condition, apart from reductions in manufacturing growth (low in all versions) and business greenness (high in all versions).

A number of commonalities can also be observed between the three versions when examining the pattern of responses as a whole and the variability of lever choices. Respondents in all conditions included relatively high levels of offshore wind, renewables and energy efficiency: indicating robust preferences (under different frames) and therefore strong generic support for these options. This is even the case in the 'high-technology' condition, which illustrates an energy future that effectively meets the carbon target without renewable technologies. Despite this initial framing, respondents still chose to include high levels of renewables in this condition. A corollary of this is that people are likely to be more prone to anchoring and reference point effects if prior preferences are less strongly held. Hence more variability is observed across the three conditions for other supply-side technologies, specifically CCS, nuclear power and biofuels, indicating less consistent preferences for these more controversial technologies. Responses here were clearly impacted by the differing starting scenarios, indicating a significant degree of uncertainty or ambivalence. Nuclear power, however, tended to be included least compared to other supply technologies irrespective of its absolute level.

Examining the demand-side, manufacturing growth and home temperature reductions were typically included at levels reflecting a reluctance to change both of these from current energy use patterns (although some variability in home temperature reductions was observed, whereby some people included greater reductions in the 'low-carbon living' condition). Other changes (e.g. changing 
heating fuel, and the way we travel) were generally included at levels that indicate acceptance of some lifestyle changes (e.g. increased use of public transport and electric vehicles), and again they were significantly impacted by the starting scenario.

Taken together, several clear public preferences with regard to energy futures emerged across all versions of the my 2050 tool, despite framing in the form of anchoring being present. Nonetheless, we did also find significant framing effects. One potential explanation is that giving people examples of potential solutions - in this case energy futures that meet the carbon target - results in less vigorous reflection by the users on the available options and on their own personal preferences. In addition, people might be particularly prone to using existing information as anchor points for options where high ambivalence, uncertainty or unfamiliarity is being experienced. Here variability across conditions with regard to some options might reflect weaker, or not yet fully formed preferences, making them particularly susceptible to framing effects (36). One feature of our data that supports this suggestion comes from the time respondents spent engaging with the tool. On average, respondents spent more time engaged in the no exemplar condition compared to the two exemplar scenario conditions (full analysis detail in Supplementary Note 2, Supplementary Figure 1 and Supplementary Table 5). Although people, on average, did spend substantial time engaging with the tool in all versions (approximately 9 to 12.5 minutes), this difference indicates that providing exemplar scenarios can lead to less time spent interrogating and reflecting on choices. However, it is also worth noting that, when comparing respondents' rated happiness with their created futures, no significant differences were found across the three versions $(F(2,1561)=1.226, p>0.05$; the average response across all versions being 'fairly happy').

\section{Effects of engaging with the my2050 tool}

Finally, we were interested in what effect engaging with the my2050 tool might have on people's more general perceptions of energy supply options and the need for demand-side change. We therefore compared relevant perceptions before and after engagement with the tool. Despite the strong climate change emphasis within my2050, we found that concern for climate change was not 
significantly different before $(\mathrm{M}=2.89, \mathrm{SD}=0.82)$ compared to after using the tool $(\mathrm{M}=2.90, \mathrm{SD}=0.81$; $F(1,2180)=0.115, p>0.05)$. Similarly, concern for energy security issues was unaffected (before $\mathrm{M}=3.17 \mathrm{SD}=0.59$, after $\mathrm{M}=3.15 \mathrm{SD}=0.58 ; \mathrm{F}(1,1927)=1.873, \mathrm{p}>0.05)$. Although we note here that concern for both climate change and energy security was high in all samples.

Perceptions of the need for demand-side change and the favourability of energy sources were however impacted (see Supplementary Note 3 and Supplementary Table 6 for full analysis detail). People's preparedness to reduce their own energy use showed a small but significant increase after engaging with the tool. With regard to different energy sources for electricity generation, a clear pattern emerged whereby people generally became slightly less favourable towards fossil fuels and more favourable towards renewable energy options. The analysis of variance test did not indicate any significant interaction between perceptions (before and after) and the three versions of the tool (original, high-technology, low-carbon living), indicating that the three versions did not impact preferences differently. This latter finding suggests that engagement with a scenario-building tool like my2050 may indeed increase certainty in people's choices and heighten the perceived need for action. We did not explore the mechanisms by which this might occur here, however it is likely that such engagement consolidates and confirms people's existing preferences while also making the implications and need for action more salient.

\section{Discussion}

Our study illustrates how scenario-building tools such as my2050 can be useful for gauging public preferences towards 'whole' energy system change, and eliciting views about energy choices in the context of each other and within the constraints set by carbon-targets and technical feasibility. The importance of doing this has been recognized previously (39), but the current study is the first to offer systematic research evidence showing how it can be successfully achieved.

Public preferences elicited through the my2050 tool are consistent with analyses of public preferences from other data (40-41). However, unlike the analysis reported by a previous study, which 
examined responses by a sample of self-selected respondents who accessed the tool online at its launch in 2011 (29), we did not find a preference for demand-side over supply-side changes. This might be due to the sample in this previous analysis being self-selected, potentially more engaged with environmental issues in advance, and hence also more inclined to accept aspects of personal change when using the tool.

In our analysis, strong public preferences exist for the inclusion of renewable energy and energy efficiency within energy futures, whereas reductions in manufacturing growth (and to some extent home temperature) were clearly avoided. One possible explanation for this latter finding is that manufacturing may be closely linked to economic prosperity in people's minds (9). In contrast, much more variability in preferences was observed for options that previous literature has found to be more unfamiliar to people, and these elicited more ambivalent preferences (such as CCS or biofuels and electric cars, 39-42). As such, when preferences are not fully formed or strong, they are also more susceptible to being influenced by the context in which they are elicited (36).

Perhaps the most important aspect of this study is the observation of framing effects, in the form of anchoring. We found that people's choices were significantly influenced by the exemplar scenarios presented to them. It is therefore possible that presenting existing scenarios to people might lead to lower critical engagement with options embedded in a scenario, especially if uncertainty or ambivalence already exists around those options. This observation is relevant beyond the my2050 tool, holding implications for any processes that seek to engage the public and stakeholders in decision-making around energy systems and strategies. In particular, responses to exemplar scenarios and scenario-building tools must be interpreted with caution when attempting to draw conclusions about underlying preferences and acceptance. One way to ensure a more robust analysis of public (or other stakeholder) perspectives would be to use multiple contrasting scenarios, in order to demonstrate where preferences are robust or, alternatively, where they are particularly prone to framing effects. This would also ensure engagement with a range of potential futures. There is evidence that such a practice has, in part, been adopted by the wider 2050 pathway project; for 
example the more complicated 2050 calculator (on which my2050 was based) includes a range of exemplar pathways suggested by government and third parties (43).

Finally, the my2050 tool enables people to explore their visions and preferences for systemwide energy transitions at the country level. Although it does so in a more realistic setting to many other previous approaches, and seems to engage people meaningfully, simply engaging with the tool does not necessarily indicate willingness to accept certain options (which is often context dependent) or to change current practices and behaviours. It can, however, reveal areas of conflict (e.g., extensive use of biofuels) and opportunities for change (e.g. responses to efficiency initiatives). It will therefore be important to integrate findings obtained from this and other tools with complementary approaches to understanding public perspectives. These conversations, and associated research, are important if society more widely is to have an effective voice in decisions about what type of future energy transition is both desirable and achievable. 


\section{Methods}

\section{The survey and my2050 tool}

A national survey instrument was developed by Cardiff University to examine public perceptions of the UK energy system and its future development. Data were collected online for this quantitative survey from 2-12 August 2012 by the professional survey company Ipsos MORI. For all participants, consent was obtained prior to taking part and the study was approved by the relevant University ethics committee. The questionnaire included questions on perceptions of key issues germane to energy system change and energy futures, including views on: policy framings such as climate change, energy security, and affordability; key energy supply options including fossil fuels, nuclear power, and wind energy; electrification of cooking, driving, and heating; demand reduction and demand side management issues; and overall system change. After completion of this questionnaire, respondents were asked to create their own energy future using the my2050 tool.

The my2050 tool is based on a more complicated calculator also available publically (43). This has been an influential development in the UK and elsewhere with similar tools now taken up in over 18 countries (e.g., Australia, Taiwan, Bangladesh, South Africa and many European countries; 44). Both the my2050 tool and the more complicated calculator have undergone various changes in recent years, although these changes have been more pronounced for the calculator rather than the my2050 tool. In the current study we used the original my2050 tool which was launched in March 2011. Supplementary Table 1 provides more detailed descriptions of each of the 14 levers that make up an energy future in my2050. In addition, we refer the reader to (29) who provide a comprehensive overview and description of the tool and its background. Further information can also be found on the relevant websites: https://www.gov.uk/guidance/2050-pathways-analysis

Before creating their own energy futures, we presented respondents with some basic information and instructions, alongside a still image of the my2050 tool:

The following interactive tool provides a simplified version of the UK energy system. We want you to explore this tool and create your vision for the UK energy system in 2050. You can change how we 
supply our electricity and fuel e.g. how we generate electricity as well as how we use that energy (e.g. how we might change our energy usage in our everyday lives).

You should keep two things in mind:

1. The tool is designed to explore how the UK can change its energy system to meet carbon emission targets. Specifically, by 2050 the UK has to reduce $\mathrm{CO}_{2}$ emissions to $20 \%$ of 1990 levels. You need to meet this target to be able to submit your 'world' and move to the next section of the survey (arrow pointing to the carbon target on image of tool).

2. You need to make sure that demand does not exceed supply (that is we don't use more energy than we are actually producing). This will be indicated on the tool - to see the indicator you need to click on this bar (arrow pointing to energy security indicator on image of tool).

We want you to create a future that you would like to live in whilst being realistic, taking into account practicalities and real constraints that you think are important.

The respondents who were assigned to one of the exemplar scenario conditions received an additional sentence before moving on to the tool: When you click 'next' and move on to the tool, you will see that a possible 'future' has already been created. This world meets the $20 \%$ target primarily by changing how we produce our energy (supply)/how we use energy (lifestyle change). Please explore this future and change it to create your own vision.

We only made one major change to the tool. In the two versions of the tool in which respondents were presented with an exemplar scenario, the starting points of all the levers were set at particular points rather than being set at 0 . The two exemplar scenarios were created by the researchers in conjunction with the scenarios created for the qualitative phase of data collection as part of the wider project (41). They represented two different but plausible futures. The first involved a highly technological response to energy issues with technologies like CCS and nuclear energy along with some renewable energy deployment and only a small amount of change on the demand side. The 
second exemplar scenario focused on high levels of renewable deployment and higher levels of change to the demand side. These were broadly modelled on scenarios available in the public domain, for example the $100 \%$ renewable energy scenario produced by the Word Wildlife Fund and the Blueprints Shell scenario (see 27-28). The exemplar scenarios were created by first adjusting the levers to represent key aspects identified to be important in each (either a lot of renewable energy with accompanying demand-side changes or high amounts of non-renewable energy supply such as CCS and nuclear). Then additional levers were adjusted to ensure the scenarios reached the carbon target and sufficient energy security (demand and supply balance).

The two exemplar scenario conditions are referred to as 'high-technology' and 'low-carbon living', but this label was not presented to participants. The final starting positions for each of the levers in the two conditions are as follows:

For the high-technology exemplar scenario: Biofuels (3), Fossil fuel reduction (1), Nuclear power (3), CCS (3), Wind-land (0), Wind-sea (0), Other renewables (0), Manufacturing growth (reductions) (1), Business greenness (1), Home efficiency (1), Home temperature reduction (0), Heating fuel (1), How we travel (1), Transport fuel (1).

For the low-carbon living exemplar scenario: Biofuels (1), Fossil fuel reduction (2), Nuclear power (0), CCS (0), Wind-land (2), Wind-sea (3), Other renewables (3), Manufacturing growth (reductions) (1), Business greenness (2), Home efficiency (3), Home temperature reduction (2), Heating fuel (2), How we travel (3), Transport fuel (2).

Finally, we made a number of other smaller changes to the appearance of the tool for this particular research study. This included removing the background noises and music, and the links to Twitter and Facebook. The version original published by the UK Department of Energy and Climate Change also included a number of screens after the submission of an energy future which summarised the respondent's choices. The text accompanying this summary was replaced with a simple message of "Thank you for submitting your world. Your future world looks like this:” Respondents are also 
asked a number of follow-up questions within the tool itself, from which we removed a question about climate change concern (because respondents are asked about this at a later stage).

Sample

A nationally-representative quota sample of the British population (i.e., England, Scotland, and Wales) aged 18 years and older completed the online survey. All respondents were taken from the Ipsos MORI Access Panel. Panellists were recruited using an email invitation including a link to the online questionnaire. The email contained information about the length of survey and incentive points. Quotas were monitored on a daily basis during fieldwork and reminder emails were sent to all panellists who had not completed the survey. Quotas were set according to key socio-demographic variables including gender, geographic region, age, and employment status to ensure broad national representation across these. The same quotas were used for the sub-samples recruited to complete the two altered versions of the my2050 tool. Quota data were based on Labour Force Survey statistics from 2006. Full sample details are available in (40).

The drop-out rate (22\%) was in line with other surveys of this kind (length and topic) and evenly distributed across all sections of the survey. Response rates are not indicative when using online quota-sampling as non-response cannot be easily defined and demographic information should be consulted instead (45).

The majority of respondents completed the my2050 tool using the original version where each respondent created their own energy future to meet the carbon reduction target $(n=1,800)$. The two sub-samples $(n=204, n=210)$ which received altered versions of the my2050 tool also contained quotas to ensure broad national representation on the demographic variables mentioned previously. After completion of the main questionnaire, respondents were randomly allocated to one of the three conditions (no exemplar, high-technology exemplar, low-carbon living exemplar) until the required sample sizes and quotas were met. There are no major differences on key demographic variables (age, gender, occupational status) between the three samples. 
Analysis

The my2050 tool enables respondents to create their own energy future using 14 supply and demand-side choices in the form of levers. Each lever has four levels where level 0 is referred to as 'no effort' and level 3 is considered 'highest effort'. High effort levels represent an increase in a particular option within the energy system: for example an increase in numbers of wind turbines or greater use of public transport. For three levers - fossil fuels, manufacturing growth, home temperature - this pattern does not hold. These sliders are moved 'down' rather than 'up', where low 'effort levels' either represent an increase or no change to that sector and higher 'effort levels' represent decreases (e.g. lowering of home temperature). For all analyses, 'no effort' is assigned 0 and 'highest effort' is assigned as level 3, irrespective of whether the lever is moved down or up within the tool.

In this paper we chose to analyse the data generated from the my2050 tool in multiple ways. In particular we examined differences between the samples completing different versions of the tool using both parametric and non-parametric statistical tests. On the one hand, the data could be considered ordinal because the labels associated with each point on a particular lever do not represent equivalent intervals. In this case non-parametric tests would be most appropriate. On the other hand, the spatial differences between each point on the lever are equivalent and it is likely that respondents interpreted them as such. We therefore provide multiple descriptive statistics including means, medians and modes and conduct the analysis using both parametric (MANOVA and follow-up tests) and non-parametric tests (Mann-Whitney U tests). Results from both types of tests are consistent with one another and we note that the overall conclusions do not change depending on the type of test and statistic used. The analyses are displayed in full in Supplementary Table 2 (descriptive statistics), Supplementary Table 3 and 4 (statistical test results).

\section{$\underline{\text { Measures }}$}

The following measures were used to examine the effect of the my2050 tool on respondents' attitudes more broadly: 
Climate change concern: How concerned, if at all, are you about climate change, sometimes referred to as 'global warming'? Higher numbers indicate more concern on a 4-point response scale (not at all concerned, not very concerned, fairly concerned, very concerned).

Energy security concern: A reliable scale (Cronbach's $\alpha$ (before) $=0.83 ;($ after $)=0.83)$ was created using six questions. How concerned, if at all, are you that in the next 10-20 years: a) electricity and gas will become unaffordable for you? b) petrol will become unaffordable for you? c) there will be frequent power cuts d) the UK will be too dependent on energy from other countries? e) there will be a national petrol shortage? f) the UK will have no alternatives in place (e.g. renewables) if fossil fuels (gas, oil) are no longer available? Responses were provided on the same scale as for climate change concern.

Preparedness to reduce own energy use was measured by creating a scale using three items $($ Cronbach's $\alpha($ before $)=0.74 ;($ after $)=0.78)$. I am prepared to greatly reduce my energy use; I am prepared to greatly reduce my energy use if support is available to help me do this; I want to reduce my energy use. Responses were provided on a 5-point agreement scale where higher numbers indicate more agreement (strongly disagree, tend to disagree, neither agree nor disagree, tend to agree, strongly agree).

Favourability towards energy sources: How favourable or unfavourable are your overall opinions or impressions of the following energy sources for producing electricity currently? Respondents indicated their favourability on a 5-point response scale where higher numbers indicate greater favourability (very unfavourable, mainly unfavourable, neither favourable nor unfavourable, mainly favourable, very favourable). The question included the following energy sources: Biomass (that is wood, energy crops, and human and animal waste), coal, gas, hydroelectric power, nuclear power, oil, sun/solar power, wind power, marine power (tidal and wave power). For analysis, responses to the three fossil fuel sources were combined to form a reliable scale (Cronbach's $\alpha$ (before) $=0.78 ;($ after $)=0.83)$. The same was done for the renewable energy sources (hydroelectric, marine, wind, sun/solar, biomass) Cronbach's $\alpha$ (before $)=0.73 ;($ after $)=0.74)$. 
Happiness with their created my2050 future: How happy are you with the world that you created? Responses were provided on a 5-point scale where higher numbers represented greater happiness (very unhappy, fairly unhappy, no opinion, fairly happy, very happy).

\section{$\underline{\text { Data Availability }}$}

A report of the questionnaire results is available (40). Data that support other findings of this study are available from the corresponding author upon reasonable request. 


\section{References}

1. IEA Annual Report: World Energy Outlook (International Energy Agency, 2016); https://www.iea.org/newsroom/news/2016/november/world-energy-outlook-2016.html

2. The Carbon Plan (UK Department of Energy and Climate Change, 2011); https://www.gov.uk/government/publications/the-carbon-plan-reducing-greenhouse-gasemissions--2

3. Watson, J., Gross, R. \& Ketsopoulou, I. Energy policy special issue: UK Energy Research Centre uncertainties project. Energ. Policy 87, 604-606 (2015).

4. 2050 Pathway Analysis (UK Department of Energy and Climate Change, 2010); https://www.gov.uk/guidance/2050-pathways-analysis

5. Foxon, T.J., Hammond, G.P. \& Pearson, P.J. Developing transition pathways for a low carbon electricity system in the UK. Technol. Forecast. Soc. 77, 1203-1213 (2010).

6. Scheer, D., Konrad, W. \& Scheel, O. Public evaluation of electricity technologies and future low-carbon portfolios in Germany and the USA. Energ. Sustain. Soc. 3(8), 1-13 (2013).

7. Ekins, P. et al. The UK Energy System in 2050: Comparing Low Carbon, Resilient Scenarios. (UK Energy Research Centre, 2013).

8. UK Future Energy Scenarios (National Grid, 2014).

9. Demski, C., Butler, C., Parkhill, K.A., Spence, A. \& Pidgeon, N. Public values for energy system change. Global Environ. Chang. 34, 59-69 (2015).

10. Butler, C., Demski, C., Parkhill, K.A., Pidgeon, N. \& Spence, A. Public values for energy futures: Framing, indeterminacy and policy making. Energ. Policy 87, 665-672 (2015).

11. Nielson, S.K. \& Karlsson, K. Energy scenarios: a review of methods, uses and suggestions for improvement. J. Global Energ. Iss. 27(3), 302-322 (2007).

12. Perlaviciute, G. \& Steg, L. The influence of values on energy alternatives. Renew. Energ. 77, 259-267 (2015).

13. Trutnevyte E., McDowall W., Tomei, J. \& Keppo I. Energy scenario choices: insights from a retrospective review of UK energy futures. Sustain. Renew. Energ. Rev. 55, 326-337 (2016).

14. Pidgeon, N., Demski, C., Butler, C., Parkhill, K.A. \& Spence, A. Creating a national citizen engagement process for energy policy. Proc. Nat. Ac. Sci. 111(Sup.), 13606-13613 (2014).

15. Miller, C.A., Iles, A. \& Jones, C.F. The social dimensions of energy transitions. Sci. Cult. 22(2), 135-148 (2013).

16. Devine-Wright. P. Explaining 'NIMBY' objections to a power line: the role of personal, place attachment and project-related factors. Environ. Behav. 45, 761-781 (2013).

17. Henwood, K. et al. Energy Biographies Research Report (Cardiff University, 2015); http://orca.cf.ac.uk/87333/

18. Sovacool, B.K. What are we doing here? Analyzing fifteen years of energy scholarship and proposing a social science research agenda. Energ. Res. Soc. Sci. 1, 1-29 (2014).

19. Goulden, M., Bedwell, B., Rennick-Egglestone, S., Rodden, T. \& Spence, A. Smart grids, smart users? The role of the user in demand side management. Energ. Res. Soc. Sci. 2, 21-29 (2014).

20. Mayer, L.A., Bruine de Bruin, W. \& Granger Morgan, M. Informed public choices for lowcarbon electricity portfolios using a computer decision tool. Environ. Sci. Technol. 48, 36403648 (2014).

21. De Best-Waldhober et al. Informed public opinions on CCS in comparison to other mitigation options. Energ. Proc. 1, 4795-4802 (2009).

22. Bessette, D.L., Arvai, J. \& Campbell-Arvai, V. Decision support framework for developing regional energy strategies. Environ. Sci. Technol. 48, 1401-1408 (2014).

23. Bessette, D.L., Campbell-Arvai, V. \& Arvai, J. Expanding the reach of participatory risk management: testing an online decision-aiding framework for informing internally consistent choices. Risk Anal. 36(5), 992-1005 (2016).

24. Jones C.R., Eiser J.R. \& Gamble T.R. Assessing the impact of framing on the comparative favourability of nuclear power as an electricity generating option in the UK. Energ. Policy 41, 451-465 (2012). 
25. Bailey, R. An exploration of the low carbon futures for the Bristol region. (PhD Thesis, University of the West of England, 2012).

26. Stagl, S. Multicriteria evaluation and public participation: the case of UK energy policy. Land Use Policy 23, 53-62 (2006).

27. Energy scenarios to 2050. (Shell Global, 2008); http://www.shell.com/content/dam/shell/static/public/downloads/brochures/corporate$\mathrm{pkg} / \mathrm{scenarios} /$ shell-energy-scenarios2050.pdf

28. The energy report. 100\% renewable energy by 2050. (World Wildlife Fund, 2011); http://www.worldwildlife.org/publications/the-energy-report

29. Allen, P. \& Chatterton, T. Carbon reduction scenarios to 2050: An explorative analysis of public preferences. Energ. Policy 63, 796-808 (2013).

30. My2050. (Department of Energy and Climate Change, 2012). A version available at http://my2050.decc.gov.uk

31. Corner, A.J. et al. Nuclear power, climate change and energy security: Exploring British public attitudes. Energ. Policy 39(9), 4823-4833 (2011).

32. Shaw, C.J. Reframing climate risk to build public support for radical emission reductions: the role of deliberative democracy. Carbon Managem. 5(4), 349-360 (2015).

33. Levin, I.P., Schneider, S.L. \& Gaeth, G.J. All frames are not created equal: A typology and critical analysis of framing effects. Organ. Behav. Hum. Dec. 76, 149-188 (1998).

34. Tversky, A. \& Kahneman, D. Judgement under uncertainty: Heuristics and biases. Science 185, 1124-1130 (1974).

35. Chapman, G.B. \& Johnson, E.J. Incorporating the irrelevant: Anchors in judgments of belief and value. In T. Gilovich, D. Griffin, \& D. Kahneman (Eds.), Heuristics and Biases: The Psychology of Intuitive Judgment (pp. 120-138) (Cambridge University Press, Cambridge, UK, 2002).

36. Lichtenstein, S. \& Slovic, P. The Construction of Preference. (Cambridge University Press, Cambridge, UK, 2006).

37. Macnaghten, P. Researching technoscientific concerns in the making: narrative structures, public responses and emerging nanotechnologies. Environ. Plan. A 42, 23-37 (2010).

38. Miller, C. The dynamics of framing environmental values and policy: Four models of societal processes. Environ. Values 9, 211-233 (2000).

39. Whitmarsh, L.E. et al. Public attitudes, understanding, and engagement in relation to lowcarbon energy. A selective review of academic and non-academic literatures. (Research Councils UK Energy Programme, 2011).

40. Demski, C., Spence, A. \& Pidgeon, N. Summary findings of a survey conducted in August 2012 - Transforming the UK Energy System: Public values, attitudes and acceptability (UK Energy Research Centre, 2013); http://www.ukerc.ac.uk/publications/transforming-the-ukenergy-system-public-values-attitudes-and-acceptability-summary-findings-from-a-surveyconducted-august-2012.html

41. Butler, C., Parkhill, K. \& Pidgeon, N. Deliberating energy transitions in the UKTransforming the UK Energy System: Public values, attitudes and acceptability (UK Energy Research Centre, 2013); http://www.ukerc.ac.uk/publications/transforming-the-uk-energysystem-public-values-attitudes-and-acceptability-deliberating-energy-system-transitions-inthe-uk.html

42. Graham-Rowe, E. et al. Mainstream consumers driving plug-in battery-electric and plug-in hybrid electric cars: A qualitative analysis of responses and evaluation. Transportation Res. A-Pol. 46(1), 140-153 (2012).

43. 2050 Calculator. (Department of Energy and Climate Change, 2016); http://2050-calculatortool.decc.gov.uk/\#/home

44. Tomei, J. et al. An early evaluation of the 2050 Calculator international outreach programme. (Institute of Sustainable Resources, University College London, 2015).

45. Dillman, D.A. Mail and Internet Surveys: The Tailored Design Method. (John Wiley, New Jersey, 2007). 


\section{Acknowledgments}

This research formed part of the programme of the UK Energy Research Centre and was supported by the UK Research Councils (NE/I006753/1 and EP/L024756/1). Additional support was received from the Welsh Government, the Leverhulme Trust (F/00 407/AG), and for Alexa Spence from Horizon Digital Economy Research EPSRC grant (EP/M02315X/1). The research team would also like to thank the project advisory panel.

\section{Author contributions}

$\mathrm{CD}$ led the design of the research, conducted data collection, performed the analysis and drafted the manuscript. AS and NP significantly contributed to the design of the study, discussion of the data analysis and writing of the manuscript.

\section{Competing Interests}

The authors declare no competing financial interests. 


\section{Figures}

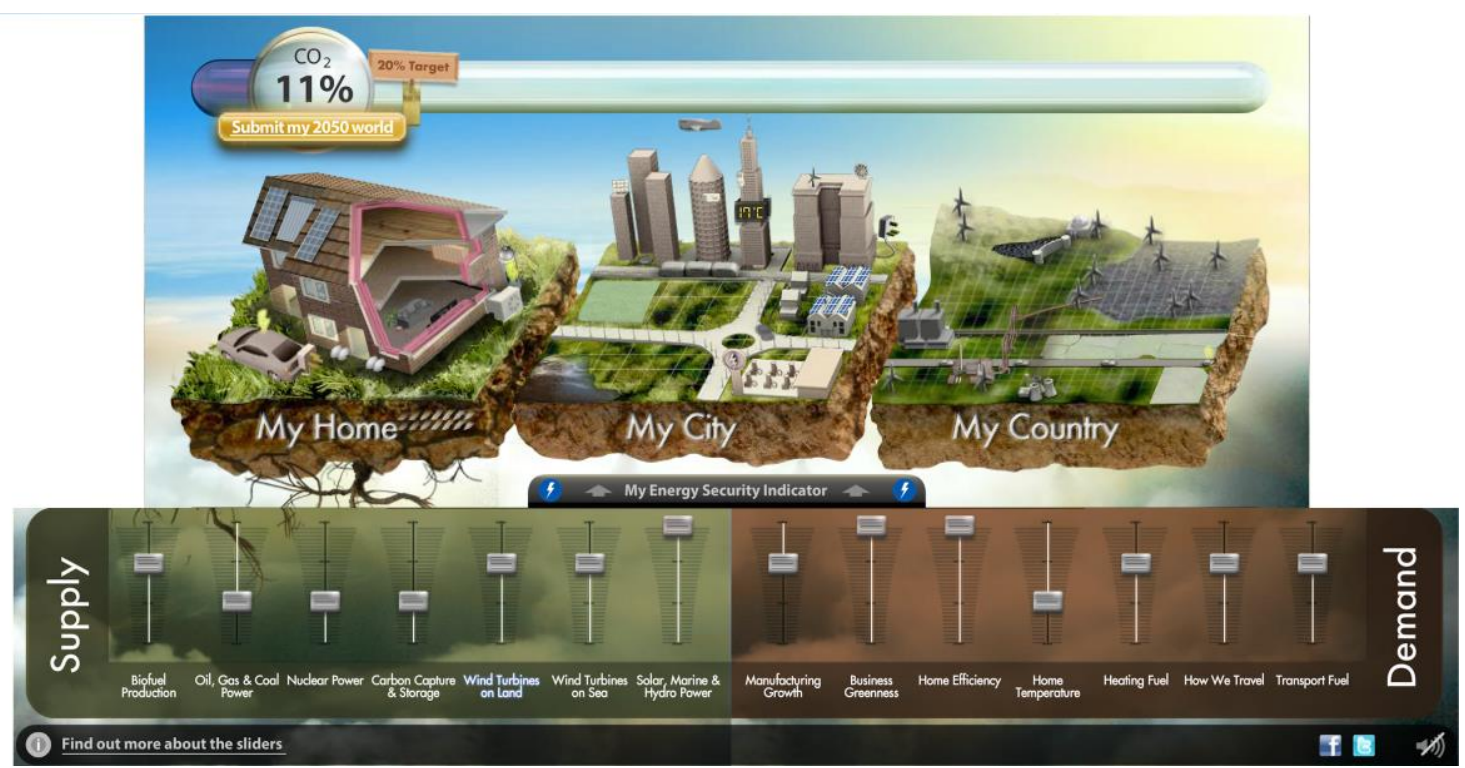

Figure 1. Screenshot of the my2050 tool. The image depicts an energy future based on modal responses for respondents completing the original version of the tool where starting positions of levers were set at 0 indicating no change to the current trajectory of that sector (no exemplar scenario presented, $\mathrm{n}=1,800$ ). Note that in this pathway supply exceeds demand by a substantial amount. Image contains public sector information licensed under the United Kingdom's Open Government License v2.0. 


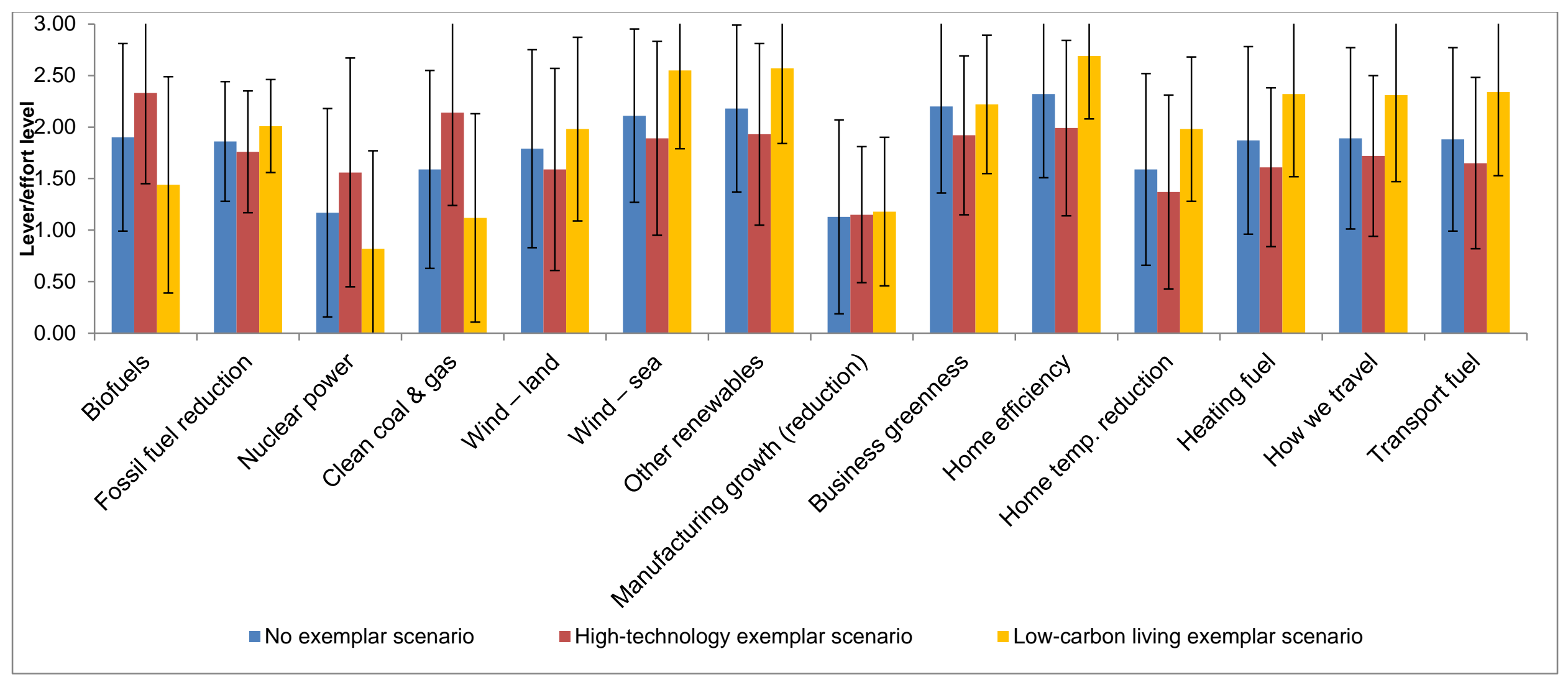

Figure 2. Responses to the my 2050 tool. Mean lever/effort level ( $0=$ no effort/change to current trajectory; $3=$ heroic measures to change current trajectory) for each of the 14 levers are presented. Error bars indicate \pm 1 standard deviation. All differences between scenario conditions are significant $(\mathrm{F}(28$,

4398)=4396,p<0.05) with the exception of manufacturing growth (all three conditions), fossil fuel reduction between the no exemplar and high-technology condition, and business greenness between the no exemplar and low-carbon living condition. Non-parametric tests confirm these findings with additional nonsignificant differences for the onshore wind lever comparing the no exemplar condition to both the high-technology and low-carbon living exemplar conditions. 

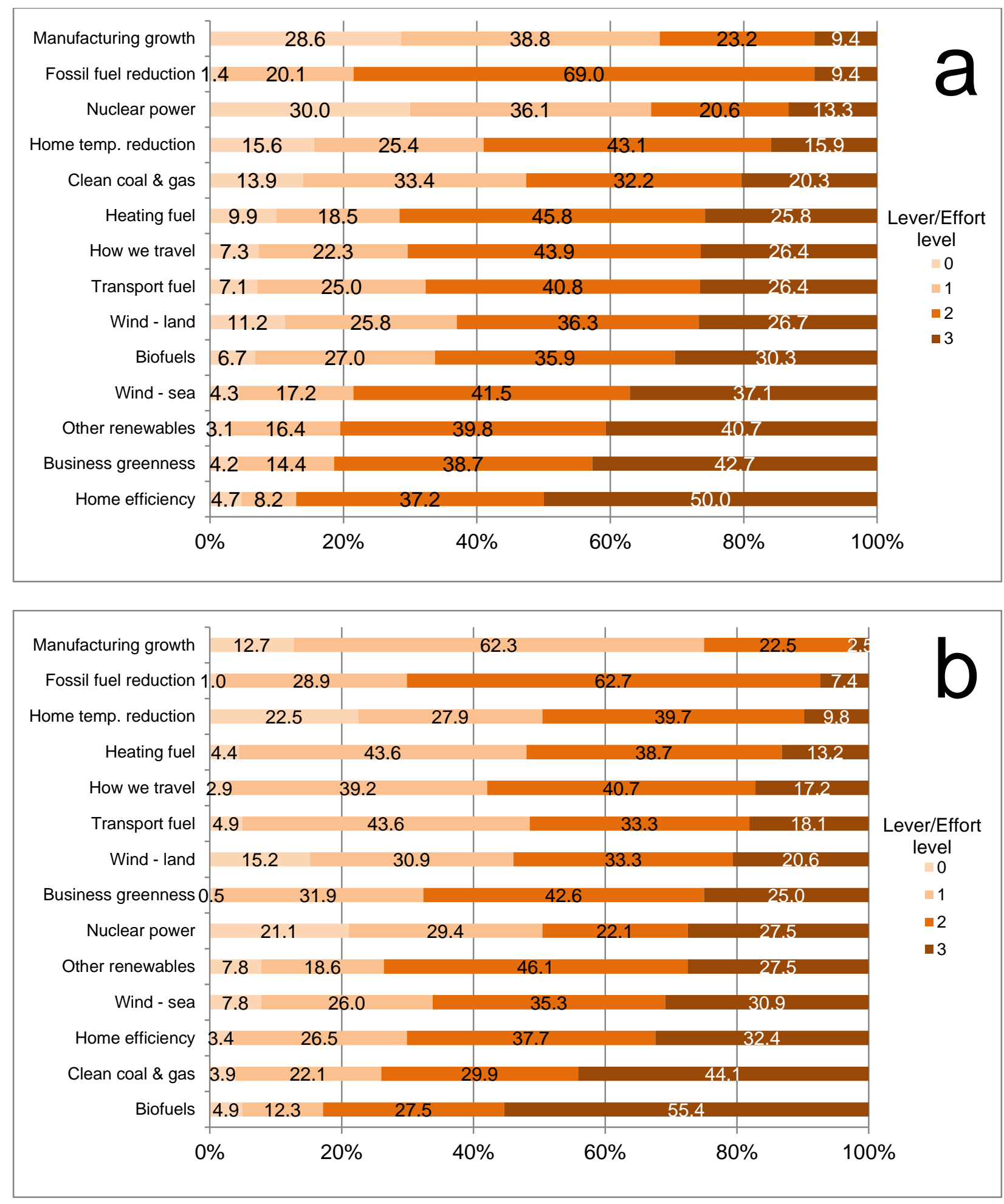


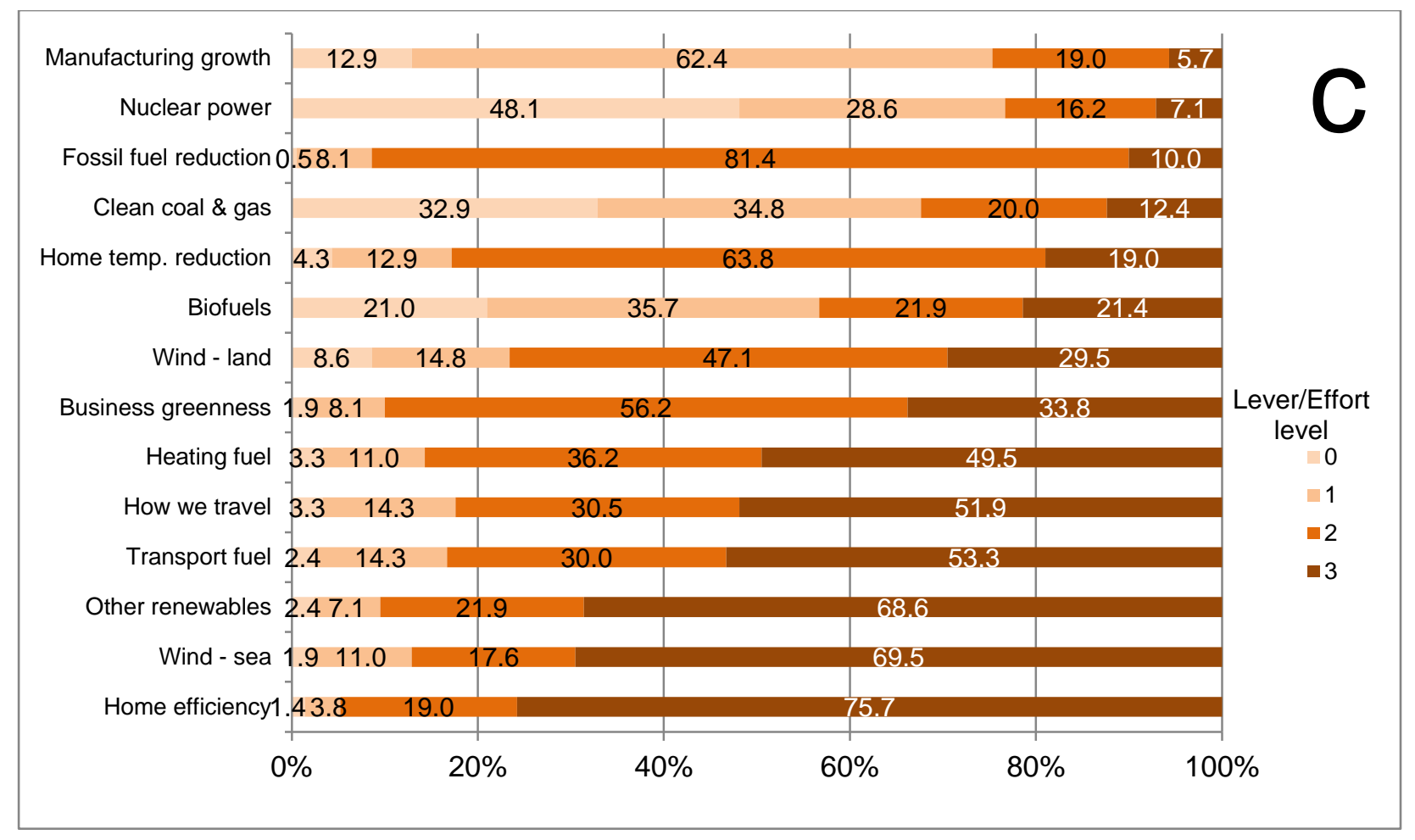

Figure 3. Responses to the three versions of the my 2050 tool. Percentage of respondents at each of the four levels ( $0=$ no effort/change to current trajectory; $3=$ heroic measures to change trajectory) for the 14 levers are shown. These are ranked by percentage of respondents choosing the top effort level/setting. Figure 3a displays responses for the original version of the my2050 tool (no exemplar scenario, $n=1,800)$. Figure $3 \mathrm{~b}$ and $3 \mathrm{c}$ display responses to the 'high-technology' $(n=204)$ and the 'low-carbon living' $(\mathrm{n}=210)$ exemplar scenario conditions respectively. 